\title{
Water Metering Pilot Project: A Case Study of Water Demand Management in the Sultanate of Oman
}

\author{
Zaher Khalid Al Suleimani* and Bushra Khalfan Al Wohaibi
}

Water Resources Affairs, Ministry of Regional Municipalities, Environment and Water Resources,

P.O. Box 461, PC. 112, Ruwi, Sultanate of Oman

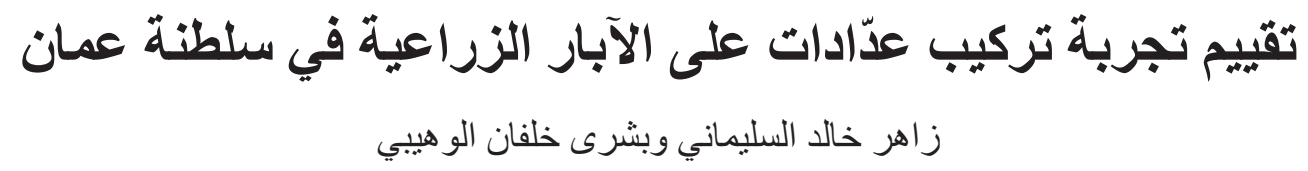

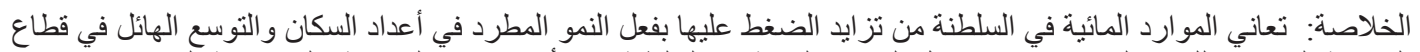

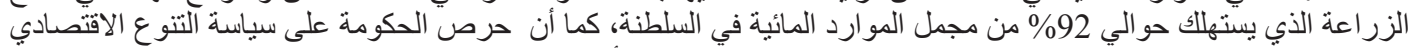

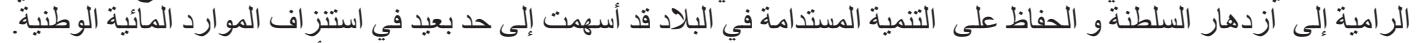

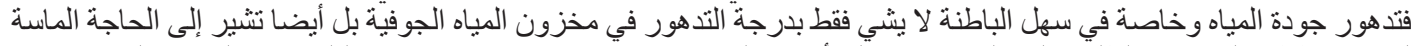

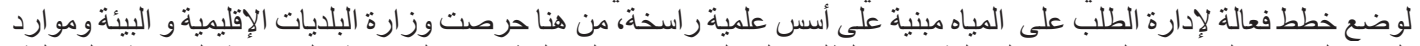

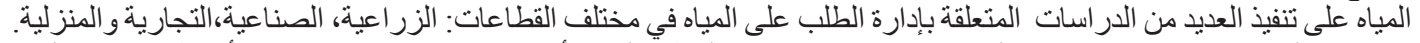

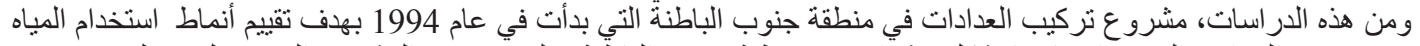

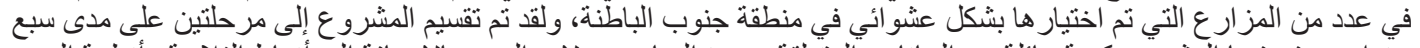

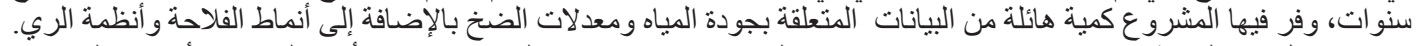

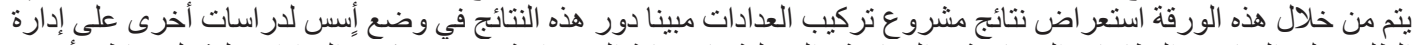

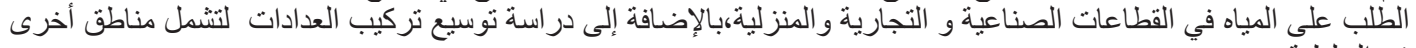

في السلطنة.

\begin{abstract}
The Sultanate of Oman is experiencing increased pressure on its groundwater resources. This is mainly due to agricultural enterprises, which consume about $92 \%$ of national water resources, as well as an upsurge in industrial, commercial and domestic water use. The ever-growing population, diversification of economic activities and the ensuing rise in national prosperity have meant an increasing demand for water. This has resulted in a marked depletion of groundwater supplies, intrusion of seawater, and deterioration of ground water quality in the case of the Al Batinah region. A scientific and effective water demand management strategy for the Sultanate is therefore needed. Accordingly, the Ministry of Regional Municipalities, Environment and Water Resources (MRMEWR) have conducted several studies related to water demand management in the agricultural, industrial and domestic sectors. One of these studies was the Water Metering Pilot Project (WMPP), initiated in 1994 with the objective of evaluating patterns of water use on a number of randomly selected farms in the southern Al-Batinah. The results obtained over a period of seven years confirm that water metering alone does not help reduce the quantity pumped. These findings have encouraged other advanced studies on water demand management in industrial, commercial, domestic and agriculture sectors in different areas of the Sultanate.
\end{abstract}

Keywords: Water meters, water abstraction, water quality.

\section{Introduction}

The Sultanate of Oman is one of the countries that have scarce renewable water resources due to its location within the arid zone characterized by low rainfall and high summer temperatures. Annual rainfall varies from $50 \mathrm{~mm} / \mathrm{yr}$, in central Oman to 300

* Corresponding author. E-mail: ddgwrw@mrmewr.gov.om 
$\mathrm{mm} / \mathrm{yr}$ in the mountain ranges, with an average of 100 $\mathrm{mm}$, of which $80 \%$ is lost by evaporation. A further $5 \%$ drains off into the seas, leaving only about $15 \%$ for aquifer recharge.

Omani traditional agriculture has maintained an unstable balance between water resources and the various uses. Furthermore, the rapid increase in population, expansions in economic activities since the renaissance, beginning from the 1970s, and the introduction of modern technology in well drilling, have added even more pressure on the situation. At present, renewable water resources in Oman are overexploited and in some areas, particularly the $\mathrm{Al}$ Batinah Coast, water abstraction far exceeds recharge rates. Consequently, groundwater levels have declined and the resulting intrusion of seawater has led to the abandonment of several farms.

This paper presents the highlights of a water metering pilot study that was conducted during the period 1994 - 2000 by the Ministry of Regional Municipalities, Environment and Water Resources for selected farms in the southern Al Batinah (MRMEWR, 2000). The objectives were to evaluate water use patterns and relate them to previous studies on water demand management in agriculture, as well as to compare different types of water meters and their adaptability to Omani conditions.

\section{Research Methodology}

\section{Selection of Farms}

The farms were selected using well inventory maps and considering farm size, cropped area, types of crops, water quality and the number of wells in each farm. The farms selected were located in the lower catchments of Wadi Taww, Al Manumah and Ma'awil, in Wilayat Barka in the southern Al Batinah. These areas were associated with deterioration in water and soil quality caused by over abstraction of water due to increasing agricultural activities.
Farmers were approached through letters to explain the objectives of the Pilot Project, after which they were administered with questionnaires to collect relevant information. The project was undertaken in two phases. The first phase started in March 1994, when one hundred and eleven water meters were installed on wells in 27 farms, covering a total area of 475.5 ha. The second phase started in 1996 and involved the installation of 315 meters on wells in 115 farms covering a total area of 1425.5 ha (Table 1). A crop survey was conducted on each farm after the installation of the water meters. The total area was recorded as well as the area allocated to each crop in each farm.

\section{Metering and Monitoring Activities}

Helical vane type meters with nominal diameters (ND) of 50, 80 and $100 \mathrm{~mm}$ were supplied by four different manufacturers and installed on the selected farms. In 1997 a water meter-testing workshop was held in Barka for the purposes of acquainting participants with procedures for the calibration and evaluation of the efficiency of the water meters installed in the farms. In order to examine its suitability for the climate of the area, each meter was calibrated, maintained and examined periodically. Meters with $10 \%$ or more variation were subjected to thorough servicing, whereas defective ones were replaced. The cost of meter installation depends on the type of the meter, the diameter and the other equipment required for installation. For this project, most of the meters were of 3 inches diameter, and the cost of installation ranged between 250 and 280 Omani Rials (US\$ 650750) per meter.

Different monitoring activities were conducted to collect data for evaluating the feasibility of this project. Monthly water meter readings were taken and water quality was checked regularly by measuring the electrical conductivity, wherever possible. Monitoring

Table 1. Farms and meters in each phase.

\begin{tabular}{lrrrrc}
\hline Phase & Year & No. Farms & No. Wells & No. Meters & Remarks \\
\hline First & 1994 & 27 & 110 & 111 & One well with two meters \\
Second & 1996 & 115 & 314 & 315 & One well with two meters \\
\hline Total & & 142 & 424 & 426 & \\
\hline
\end{tabular}


Table 2. Crop survey.

\begin{tabular}{|c|c|c|c|c|c|c|c|c|}
\hline \multirow{3}{*}{$\begin{array}{l}\text { Year } \\
\text { No. of Farms } \\
\text { Area/Percentage }\end{array}$} & \multicolumn{2}{|c|}{1994} & \multicolumn{2}{|c|}{1996} & \multicolumn{2}{|c|}{1998} & \multicolumn{2}{|c|}{2000} \\
\hline & \multicolumn{2}{|c|}{27} & \multicolumn{2}{|c|}{115} & \multicolumn{2}{|c|}{142} & \multicolumn{2}{|c|}{33} \\
\hline & ha & $\%$ & ha & $\%$ & ha & $\%$ & ha & $\%$ \\
\hline Alfalfa & 10.50 & 3 & 76.06 & 8 & 54.18 & 4 & 24.36 & 14 \\
\hline Dates & 85.68 & 21 & 143.64 & 16 & 236.80 & 20 & 36.12 & 21 \\
\hline Grass & 99.54 & 25 & 356.58 & 39 & 418.32 & 35 & 52.50 & 30 \\
\hline Citrus \& Mango & 42.84 & 11 & 133.56 & 15 & 161.28 & 13 & 17.64 & 10 \\
\hline Winter vegetables & 81.06 & 20 & 68.46 & 8 & 136.90 & 11 & 13.86 & 8 \\
\hline Mixed tree & 79.38 & 20 & 126.42 & 14 & 199.90 & 17 & 28.14 & 16 \\
\hline Total (ha) & 400 & & 905 & & 1207.5 & & 173.04 & \\
\hline
\end{tabular}

activities also included periodic surveys of cropping patterns and irrigation methods in each farm plot. In particular, data on uniformity of sprinkler and bubbler systems were collected from 41 farms in 1999.

\section{Results and Discussion}

\section{Crop Survey}

Results of the crop survey showed that the total area in the first phase (1994) was 475.44 ha for 27 farms, and the cropped area amounted to 400 ha, of which $25 \%$ was covered by grass, while palm trees represented $21 \%$ (Table 2). Winter vegetables covered 20\% of the entire area, mixed trees accounted for $20 \%$, while citrus and mango accounted for $11 \%$. In the second phase (1996), 115 farms covering an area of 1,425 ha were studied. Of the entire area, 905 ha were cultivated with the following proportion of crops and trees: grass (39\%), palm trees $(16 \%)$, vegetables $(8 \%)$, mixed trees (14\%) and citrus and mango (15\%). In 1998, 142 farms with a total area of 1979.5 ha were studied in phases one and two. Of the entire area, 1,207 ha or $61 \%$ of the total area was covered with vegetation. A breakdown of the cropping pattern shows that grass covered $35 \%$ of the area while palm trees covered $20 \%$, vegetables accounted for $11 \%$, mixed trees covered $17 \%$ and citrus and mango occupied 13\%. In 2000 the final crop survey was conducted over 33 farms, of which 6 were from the first phase and 27 from the second phase. The total cropped area was 173.04 ha, with grass covering $30 \%$, palm trees, $21 \%$, vegetables $8 \%$, mixed trees $16 \%$ of the area and citrus and mango covered $10 \%$.

\section{Water Abstraction}

Annual water abstraction in the 142 farms covered in the project varied from one year to another due to the changes in the size of the cropped area (Table 3). It was observed that the lowest average abstraction rate per hectare occurred in 1994, during the first phase, with an average of $17,850 \mathrm{~m}^{3} / \mathrm{ha} /$ year. Conversely, the maximum average abstraction rate took place in 2000 with an average of $24,220 \mathrm{~m}^{3} / \mathrm{ha} /$ year, and this increase was attributed to the expansion of the area cultivated with grass and alfalfa, covering $44 \%$ of the total cropped area, as shown in the last column of Table 2 .

\section{Irrigation Systems}

Modern irrigation was applied in $60 \%$ of the total cropped area (Table 4). The irrigation methods

Table 3. Cropped area and average water abstraction per hectare.

\begin{tabular}{lrrrr}
\hline & $\mathbf{1 9 9 4}$ & $\mathbf{1 9 9 6}$ & $\mathbf{1 9 9 8}$ & $\mathbf{2 0 0 0}$ \\
\hline Water abstracted $\left(\mathrm{m}^{3}\right)$ & 712,811 & $18,804,561$ & $24,733,562$ & $4,191,066$ \\
Cropped area $(\mathrm{ha})$ & 400 & 905.1 & 1207.5 & 173.04 \\
Average abstraction rate $\left(\mathrm{m}^{3} / \mathrm{ha} /\right.$ year $)$ & 17,580 & 20,778 & 20,483 & 24,220 \\
\hline
\end{tabular}


Table 4. Area covered by different irrigation systems.

\begin{tabular}{lcc}
\hline Irrigation System & Area (ha) & \% \\
\hline Drip & 238 & 8 \\
Bubbler & 194 & 7 \\
Sprinkler & 477 & 17 \\
Spray Gun & 852 & 30 \\
Flood & 1114 & 38 \\
\hline Total & 2875 & 100 \\
\hline
\end{tabular}

included flooding, which was used in $39 \%$ of the cropped areas, and spray guns, used in $30 \%$ of the area. Other methods were sprinklers, used in $17 \%$ of the area, bubblers applied in $7 \%$ of the area, and drip irrigation, which served $8 \%$ of the area.

\section{Water Requirements}

The average abstraction rate per cropped area is considered a good indicator of the efficiency of water use in agriculture, and water consumption per unit area is the index for measuring water loss. Data obtained from the 1998 survey was used to calculate water losses, as it covered the largest number of farms.

The water requirement for the farms was based on the studies conducted by the Ministry of Agriculture and Fisheries (MAF, 1995), and converted to the requirement per unit area by the assumption that every ha contains 250 palm trees or 386 trees (citrus and mango). The water abstraction was $24.7 \mathrm{Mm}^{3}$, with an abstraction rate of $20,481 \mathrm{~m}^{3} / \mathrm{ha}$. Comparisons indicated that 75 farms over-abstracted water, whereas 67 farms abstracted less than the crop water requirement and accounted for $37 \%$ of the total water abstraction. The total water over-abstraction was estimated to $17 \%$. In 2000 the water requirements were estimated to $32.1 \mathrm{Mm}^{3}$, while the total water pumped, according to meter readings was $41.9 \mathrm{Mm}^{3}$ resulting in $30 \%$ water over-abstraction. The results obtained over a period of seven years (Table 5) confirm that water metering alone does not help reduce the quantity pumped as over-abstraction ranged from 17 to $30 \%$.

\section{Water Quality}

Over-abstraction caused a decrease in the water table and an increase of water salinity due to direct intrusion of sea water. The quality of water in 375 wells was monitored. By comparing the 2000 data with 1996 data, it was observed that 228 , or $61 \%$ of the wells, suffered an increase in salinity by more than $20 \%$ compared with 1996. Furthermore, it was observed that 86 wells $(23 \%)$ suffered an increase in salinity ranging from 1 to $20 \%$. On the other hand, there were 61 wells $(16 \%)$ which had a decrease in salinity, with 20 of them reducing salinity by as much as $20 \%$. Most of these wells are located in the recharge areas of the Wadi Alfulaij and Wadi Taw recharge dams.

\section{Water Meter Performance}

The results of water meters performance tests indicated that Irmaj meters recorded the highest accuracy level at $93 \%$, while Kent scored $89 \%$ (Table 6). Meinecke brand had an efficiency of $88 \%$, and Wolltex was $84 \%$ accurate. Though they were not the most accurate, Kent meters showed a better capability to adapt to climatic conditions and water quality with only $4 \%$ replacement compared to Woltex, which recorded $15 \%$, and Meinecke with $26 \%$. By far the most vulnerable was Irmaj, with $60 \%$ replacement. The performance of water meters was affected by a variety of technical and environmental problems, such as, the inability of the meters to read more than 999999 , the rusting of the screws due to their vulnerability to saline water, the damage of the impeller as a result of the accumulation of sand, and dirt due to the absence of filters.

\section{Further Studies in Water Demand Management}

Based on the findings of this pilot project, especially the observation of over-abstraction of water and the salinization phenomenon, the MRMEWR launched four different demand management oriented studies. The aims of these studies was to assess the possible alternatives to control water demand rather than supply in the agricultural, industrial, commercial and domestic sectors. The following are brief descriptions of some of such studies.

\section{Study on water demand management in the industrial and commercial sectors}

This study aimed primarily at industrial and commercial establishments like hotels, restaurants, private schools and private hospitals and other organizations that rely on groundwater. This study is meant to serve as a benchmark and reference for policy and decision-making as well as an evaluation tool for future water allocation and tariff options in the commercial and industrial sector. The study, which is 
Table 6. Performance of different water meters.

\begin{tabular}{lrrr}
\hline $\begin{array}{l}\text { Meter } \\
\text { type }\end{array}$ & $\begin{array}{r}\text { Reading } \\
\text { accuracy } \\
(\mathbf{\% )}\end{array}$ & $\begin{array}{r}\text { Damaged } \\
(\%)\end{array}$ & $\begin{array}{r}\text { Replaced } \\
(\%)\end{array}$ \\
\hline Irmaj & 93 & 57 & 60 \\
Kent & 89 & 2 & 4 \\
Meinecke & 88 & 5 & 26 \\
Wolltex & 84 & 36 & 15 \\
\hline
\end{tabular}

expected to last for a period of 16 months, commenced in August 2005 and should be completed by November 2006.

\section{Technical and financial study on installing water meters on tube wells}

The aim of this study is to assess the technical and financial feasibility of installing water meters on tube wells throughout Oman to control water abstraction, and assess the policy implications of such a mechanism. The project is expected to help policy makers have a better view in water resources management with detailed data for the allocation of groundwater resources, especially operational agricultural tube wells. The study commenced in August 2005 and is due in April 2006.

On farm water demand management practices using water saving technologies and modern irrigation systems

The focus of this study is to evaluate the efficiency of modern irrigation systems along with new control and management instruments, such as scheduling, applied for the prevention of water loss. The study commenced in August 2005 and should be completed by February 2007.

Pilot study for improving domestic water demand efficiency using water saving technologies

This study aims at assessing the adaptability of water saving technologies in the Omani setting. The study commenced in June 2005 and should be completed by May 2006.

\section{Conclusions}

Over the period 1994 - 2000 total water abstraction from a representative sample of metered wells exceeded the water requirements by 17 to $30 \%$. 
Fifty-three percent of the total number of farms were responsible for $63 \%$ of total abstraction, and were causing the problem of over-abstraction. This implies that not all farmers are overpumping. However, the $63 \%$ of those who are overpumping are causing damage to water resources of the whole community. Salinity increased in $84 \%$ of the wells, with $61 \%$ recording more than $20 \%$ increase and another $23 \%$ experiencing an increase in salinity by 1 to $20 \%$. These results clearly indicate that installing water meters does not solve the problem of over-abstraction, unless it is accompanied by other control measures. On the other hand, $16 \%$ of the monitored wells located on the recharge areas of Wadi al Fulaij dam recorded a decrease in salinity by as much as $20 \%$. This shows the importance of dams in recharging aquifers. In regard to meter suitability, Kent water meters proved to be the best among the four brands tested, in terms of accuracy of measurement of water, resistance to salinity and accumulation of sand and dirt due to the absence of filters and to harsh weather conditions.
The water metering pilot project allowed estimation of overpumping in the agricultural sector and showed the need to undertake more advanced studies on water demand control and management.

\section{References}

MRMEWR (Ministry of Regional Municipalities, Environmental and Water Resources). 2001. Water metering pilot project data compilation report. Directorate General of Water Resources Management, MRMEWR, Sultanate of Oman. pp. 10-83.

MAF (Ministry of Agriculture and Fisheries). 1995. A guiding manual for water requirement for crops in the Sultanate. Ministry of Agriculture and Fisheries pp. 3-20.

Rout, R.S. 1995. Social and economic aspects of water metering in the Sultanate of Oman. International Conference on Water Resources Management in Arid Countries, Muscat, Sultanate of Oman, 12-16 March 1995. pp 25-30. 